\title{
Cultural Differences and End-User Computing
}

\author{
Thippaya Chintakovid \\ College of Information Science and Technology \\ Drexel University, Philadelphia, PA 19104 \\ Thippaya.Chintakovid@cis.drexel.edu
}

\section{Introduction}

Most computer applications are designed and developed by researchers and designers in North America. These researchers and designers unintentionally apply their cultural values and systems of thought while designing and developing computer applications. Even though some development organizations, such as Microsoft, now take cultural issues into account, most of the cultural issues considered involve language translation and visual aspects of the interface rather than the underlying structure of the application. As a result, users who are culturally different from the researchers and designers might have difficulty using the computer applications.

Hofstede [1] identified five dimensions on which cultural groups vary. Other research on systems of thought [4] has indicated that Americans and Japanese have different foci of attention. Americans are likely to focus more on a focal object, whereas Japanese tend to focus more on contextual or situational factors rather than each individual object.

In addition, Beckwith et al. [2] discovered that males and females were different in spreadsheet feature acceptance and use, which significantly impacted their effectiveness in debugging.

Hofstede's work and the above gender results raise the question whether cross-cultural effects exist in end-user computing that impact end-user effectiveness. The general research question that I address is whether people from different cultures interact differently with end-user software and whether Hofstede's five dimensions can explain the differences. More specifically, I ask whether culture impacts people's willingness to learn and use features of software to accomplish end-user programming tasks. In this work, I define the term "end user" as a computer application user who uses not only the features provided with the software, but also engages in end-user programming in order to complete a task. An example of end-user programming is creating formulas in a spreadsheet program. An empirical study of culturally diverse end users from different countries, who perform end-user programming tasks, is proposed. The findings of this study will help verify whether cultural effects exist in the design of software features that inhibit effective end-user programming.

\section{Related work}

Apart from research on cultural differences in other fields [1,4], there only is a small amount of research particularly investigating cultural differences in end-user computing $[5,6]$.

Ein-Dor and Segev [6] collected data from end users in the USA and Israel. The study investigated the effect of national environments on four issues: organization, structure, procedure, and behavior. The result showed that the two cultures were very different in terms of structural issues, i.e., the types and quantity of end-user equipment, the computer applications used, and the location of data used. Regarding procedural issues, the two samples exhibited two different patterns of the sources of computer applications used. Israeli samples used a higher number of computer applications that were developed in-house. The authors explained this difference might be because off-the-shelf applications were mostly in English and not suitable for Israeli users.

Igbaria and Zviran [5] investigated the effect of cultural differences on end-user effectiveness between Israeli and US managers. The research model used in this study consisted of three sets of variables: individual and organizational characteristics, attitudes toward end-user computing, and end-user effectiveness, which was measured by end-user satisfaction and system usage. The data were collected by means of questionnaires. The results showed that Israeli managers had more computer experience and training, whereas US managers reported a much higher level of information center support and 
exhibited more favorable attitudes toward end-user computing. In terms of end-user satisfaction and overall system usage, US managers were less satisfied with their information systems and used them less frequently, while Israeli managers reported using the system for fewer tasks and features.

Apparently, these studies investigated the effect of national environments on end-user computing from a high-level, organizational and managerial perspective.

\section{Proposed study}

Prior research merely focuses on managers' interactions with software rather than end users'. Furthermore, the managers reported on tasks using applications but not end-user programming tasks. In terms of methodology, the results are based entirely on self-reports. There was no empirical study of actual end users carrying out end-user programming tasks. Moreover, these studies were conducted in the early 1990s and targeted only US and Israeli cultures. It is likely that end-user computing in the US and other countries has changed since then. Thus, this research proposes to empirically study whether people from different countries interact differently in using enduser programmable software features.

\subsection{Design}

The system used in the study will be Forms $/ 3$ with WYSIWYT [2]. Initially a think-aloud study will be carried out. A think-aloud study will give an initial sense of whether there are cultural differences in feature acceptance and use. The study will be conducted in a controlled setting. Participants will be assigned to work on a task that is culturally unbiased. Verbalizations and end users' interaction with the application will be recorded for qualitative analysis, similar to procedures done in [3]. If cultural differences appear in feature acceptance and use, a large quantitative study will be carried out to confirm the results [2].

The second phase of the study will improve the system according to the results from the think-aloud and quantitative studies. The improved system will then be used by participants in a controlled setting to determine whether participants can better use the system to accomplish their tasks.

\subsection{Participants}

US and Thai business students will take part in the study. These two nationalities have been selected because they are from different cultural roots. Asian cultures have been shown to differ from western cultures on several of Hofstede's cultural dimensions $[1,4]$. In addition, Thailand and the US are not equal in terms of economic development, which also may lead to differences on the cultural dimensions. It is possible that Thai users may be disadvantaged by the design of systems that are developed by researchers and designers in the western hemisphere. Specifically, I will look at Thai users in Thailand.

\subsection{Materials}

Forms/3 is a spreadsheet environment, and WYSIWYT (What You See Is What You Test) is an enhancement that allows end users to take advantage of visual cues to test for errors in their spreadsheets. This environment is equipped with features such as data flow arrows, explanation-based tooltips, and the ability to mark values as correct or incorrect. Since Forms $/ 3$ is a spreadsheet environment, tasks given to participants to work on will be common spreadsheet tasks. The tasks will be designed so that they are compatible with both cultures.

Spreadsheets are commonly used in the business domain, so business students are appropriate for this study. Furthermore, both US and Thai business students are exposed to the same conceptual model of spreadsheets. Forms/3 is appropriate to use because it can be considered culture independent since this environment is new to both US and Thai participants, thereby reducing bias based on past experiences.

\section{References}

[1] Hofstede, G., Culture's Consequences: Comparing Values, Behaviors, Institutions, and Organizations Across Nations. Sage Publications, Thousand Oaks, CA, 2001.

[2] Beckwith, L., Burnett, M., Wiedenbeck, S., Cook, C., Sorte, S., and Hastings, M., Effectiveness of end-user debugging software features: Are there gender issues? Proc. of ACM Conf on Human-Computer Interaction 2005, 869878.

[3] Beckwith, L., Chintakovid, T., Wiedenbeck, S. and Burnett, M., Mining qualitative behavioral data from quantitative data: A case study from the Gender HCI Project. PPIG 2005.

[4] Masuda, T., and Nisbett, R. E., Culture and Attention to Object vs. Field. Unpublished manuscipt, University of Michigan, 2001.

[5] Igbaria, M. and Zviran, M., End-user effectiveness: A cross-cultural examination. OMEGA Int. J. of Mgmt. Sci., 19(5), 1991, 369-379.

[6] Ein-Dor, P. and Segev, E., End-user computing: A crosscultural study. Proc. of the Twenty-Third Annual Hawaii International Conference on System Sciences 1990, Vol. 4, IEEE, 1990, 240-250. 